\title{
AN AMERICIUM-FUELED GAS CORE NUCLEAR ROCKET
}

Terry Kammash, David L. Galbraith, and Ta-Rong Jan

Department of Nuclear Engineering

The University of Michigan

Ann Arbor, MI 48109

(313) 764-0205

\begin{abstract}
A gas core fission reactor that utilizes americium in place of uranium is examined for potential utilization as a nuclear rocket for space propulsion. The isomer ${ }^{242} \mathrm{~m}$ Am with a half life of 141 years is obtained from an $(\mathrm{n}, \gamma)$ capture reaction with ${ }^{241} \mathrm{Am}$, and has the highest known thermal fission cross section. We consider a $7500 \mathrm{MW}$ reactor, whose propulsion characteristics with ${ }^{235} \mathrm{U}$ have already been established, and re-examine it using americium. We find that the same performance can be achieved at a comparable fuel density, and a radial size reduction (of both core and moderator/reflector) of about $70 \%$.
\end{abstract}

\section{INTRODUCTION}

The open cycle gas core (Ragsdale 1990) fission reactor (GCR) has been identified as a promising advanced propulsion scheme that could readily meet the objectives of the space exploration initiative (SEI) of sending a manned mission to Mars in the early part of the next century. The principle of operation in this system involves a critical fissile core in the form of a gaseous plasma that heats, through radiation, a hydrogen propellant which exits through a nozzle, thereby converting thermal energy into thrust as illustrated in Figure 1.

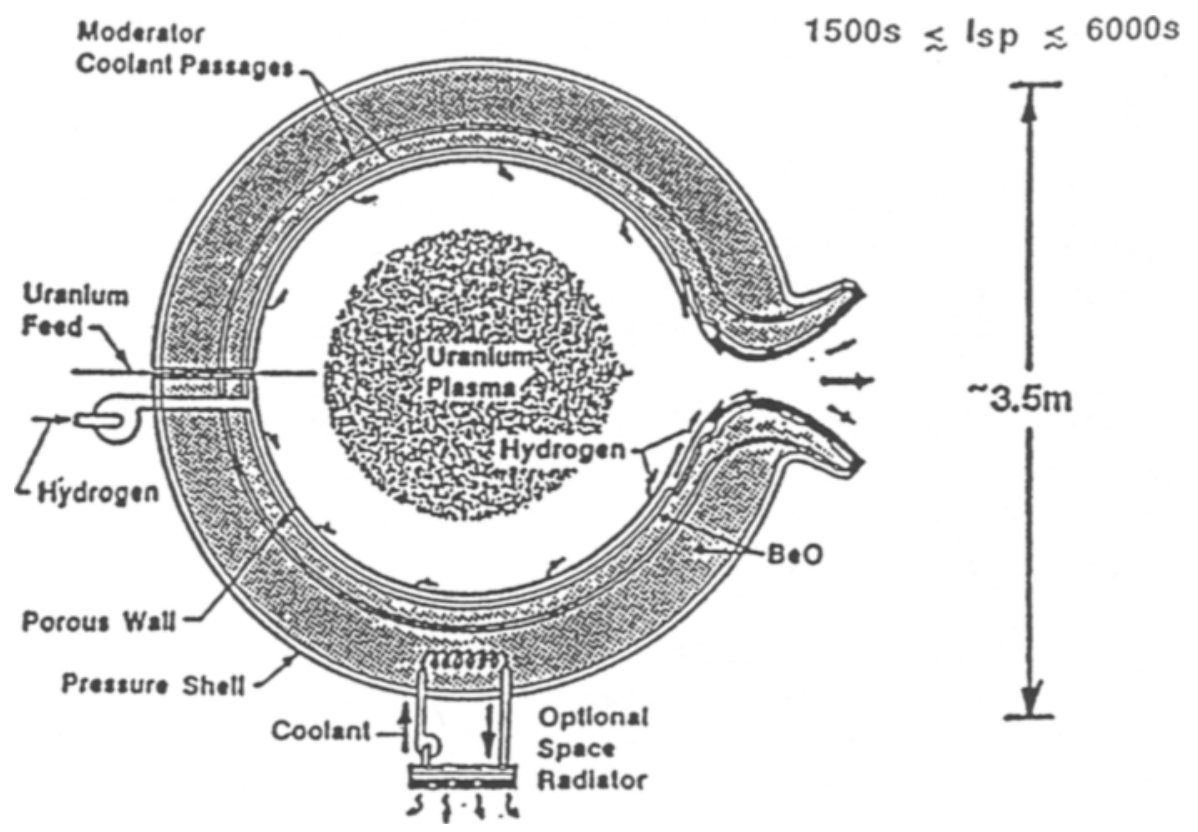

FIGURE 1. High Specific Impulse, Porous Wall Gas Core Engine (Courtesy of NASA, Lewis Research Center). 
In contrast to solid core reactors where temperature limitations, imposed by material melting, place severe constraints on rocket performance, the gas core concept circumvents these limitations because the nuclear fuel is allowed to exist in a high temperature $(10,000-100,000 \mathrm{~K})$, partially ionized state referred to as the plasma. Nuclear heat released as thermal radiation from the surface is absorbed by a surrounding envelope of seeded hydrogen propellant which is then expanded through a nozzle to generate thrust. With this scheme, specific impulses of several thousand seconds appear to be feasible (Ragsdale 1990).

In a recent paper (Kammash and Galbraith 1992), we examined some of the physics issues associated with fuel confinement and stability in GCR. We found that steady state operation of the reactor is possible only for certain core profiles which may not always be compatible with the radiative aspect of the system. Moreover, we found that the system is susceptible to hydrodynamic and acoustic instabilities that could deplete the fuel in a short time if not properly addressed. In the absence of such problems, however, the propulsion characteristics of GCR can be assessed using a heat transfer model that utilizes a diffusion heat transfer analysis which takes into account the wall material temperature and heat flux limits (Poston and Kammash 1992). It is found that for a $7.5 \mathrm{GW}$ reactor with a propellant flow rate of $5 \mathrm{~kg} / \mathrm{s}$, a specific impulse of $3300 \mathrm{~s}$ and a thrust of $200 \mathrm{kN}$ can be obtained for a maximum heat flux of $100 \mathrm{MW} / \mathrm{m}^{2}$.

None of the physics and engineering problems that face the development of the gas core nuclear rocket is perhaps more challenging than that associated with startup. One of the proposed solutions to this problem that might become feasible in the time period when GCR might become a propulsion contender, is the use of antiproton annihilation to generate the required number of neutrons (Jan and Kammash 1992). In calculating the amount of antihydrogen needed, a model consisting of a "cavity" reactor surrounded by a reflector-moderator is utilized, in which moderation of fast neutrons in the core is neglected, and thermal neutrons generated in the moderator-reflector enter the core to initiate the fission reactions. A two-group theory utilizing the time-dependent Fermi age and diffusion equations is used in which the fast neutron source is taken to consist of those resulting from the annihilation reactions and those resulting from the fission reactions taking place in the core. $\mathrm{A}_{2} \mathrm{O}$ moderator at room temperature is assumed, an effective multiplication factor, $\mathrm{k}_{\mathrm{eff}}$ is calculated, and a power balance equation is utilized to calculate the neutron source strength needed to start the reactor. For the reactor described above, a source of about $10^{22}$ neutrons was found to be adequate for the startup.

\section{Reactor Fueled with Americium}

One of the isomers of americium-242 is $242 \mathrm{~m} A m$; it has a half-life of 141 years and has the highest known thermal fission cross section. It is obtained from an $(n, \gamma)$ capture reaction with ${ }^{241} \mathrm{Am}$ which itself has a relatively high thermal capture cross section (Ronen and Leibson 1988). The isotope ${ }^{241} \mathrm{Am}$, with a half-life of 433 years, is obtained from the beta decay of ${ }^{241} \mathrm{Pu}$ which has a half-life of 14.4 years.

All these facts, namely high thermal fission cross section, relatively low capture cross section, relatively high $v$ (the number of neutrons produced per thermal fission), and long half-life make the isomer $242 \mathrm{~m}$ Am a very attractive nuclear fuel where lower fuel weight (reactor size) is important such as in space applications. The important thermal data for this isotope are given in Table 1.

This isotope decays mostly by internal conversion $(99.52 \%)$ to ${ }^{242} \mathrm{Am}$, and by alpha emission at $0.48 \%$ with an energy of $5.585 \mathrm{MeV}$. The isotope ${ }^{242} \mathrm{Am}$ in turn decays mostly $(82.7 \%)$ by beta emission to ${ }_{96}^{242} \mathrm{Cm}$ which in turn decays by alpha emission (with $6.2158 \mathrm{MeV}$ ) at a half-life of 163 days. The other branch of decay of ${ }_{95}^{242} \mathrm{Am}$ is by electron capture (17.3\%) to ${ }_{94}^{242} \mathrm{Pu}$ which in turn decays by alpha emission (with $4.983 \mathrm{MeV}$ ) at a half-life of $3.76 \times 10^{5}$ years. 
TABLE 1. Thermal Data for $242 \mathrm{~m}$ A m.

Property $\quad$ Value

1. Fission neutron yield per thermal neutron absorbed $\eta=v \sigma_{f} / \sigma_{a}$

2. Number of Neutrons produced per thermal fission $v$

3. Thermal absorption $8000 \mathrm{~b}$ cross-section; $\sigma_{\mathrm{a}}=\sigma_{\gamma}+\sigma_{\mathrm{f}}$

4. Fission Cross-section

$6600 \pm 300 \mathrm{~b}(\text { or } 7350 \pm 500 \mathrm{~b})^{\mathrm{a}}$

5. Radiative Cross-section, $\sigma_{\gamma}$

$1400 \pm 860 \mathrm{~b}(\text { or } 1650 \pm 400 \mathrm{~b})^{\mathrm{a}}$

a From Ronen and Leibson 1988.

It is useful to examine this information to see whether the decay scheme of $242 \mathrm{~m}$ Am leads to heating of the fuel so as to maintain it in a plasma form that is compatible with a gas core reactor. The range of an alpha particle of energy of $5.585 \mathrm{MeV}$ in an americium gas of density $\sim 10^{18} \mathrm{~cm}^{-3}$ is about $45 \mathrm{~cm}$ which, as we will note shortly, is approximately the desired size. With an ionization potential of $5.655 \mathrm{eV}$, we compare this value to the energy per atom associated with the alpha decay which we can readily calculate to be $8.700 \times 10^{-4} \mathrm{eV} / \mathrm{s}$. This means that, in the absence of radiation loss, it takes approximately two hours of decay to generate the ionization energy of 5.655 $\mathrm{eV}$. However, the black body radiation from such a system is about $10^{7} \mathrm{eV} / \mathrm{atom}-\mathrm{s}$, and the bremsstrahlung radiation (assuming instant ionization) is about $2.693 \times 10^{5} \mathrm{eV} / \mathrm{atoms}-\mathrm{s}$, thus the alpha decay is totally inadequate for ionizing the medium, and one must rely on the fission energy to achieve this objective.

As pointed out earlier, ${ }^{242 \mathrm{~m}} \mathrm{Am}$ is obtained from an (n, $\gamma$ ) capture reaction with ${ }^{241} \mathrm{Am}$, and since it has a high thermal fission cross-section itself, it would appear that due to the two competing processes, very little of $242 \mathrm{~m} A m$ would accumulate unless a steady supply ${ }^{241} \mathrm{Am}$ is provided. For a spherical reactor that produces $7.5 \mathrm{GW}$ of power with ${ }^{242 \mathrm{~m}} \mathrm{Am}$ fuel, at a density of $10^{18} \mathrm{~cm}^{-3}$ and a radius of $40 \mathrm{~cm}$, a thermal neutron flux of $1.462 \times 10^{17}$ $\mathrm{cm}^{-2} \mathrm{~s}^{-1}$ would be required. Noting however that each neutron captured by ${ }_{95}^{241} \mathrm{Am}$ gives rise to $5.5 \mathrm{MeV}$ in gammas, each $242 \mathrm{~m} A m$ gives $190 \mathrm{MeV}$ in capturable fission energy, and each $242 \mathrm{~m}$ Am neutron capture gives rise to $6.32 \mathrm{MeV}$ in gammas, then, on the average, each neutron absorbed in $242 \mathrm{~m} A m$ gives:

$$
\left(\frac{\sigma_{f}}{\sigma_{f}+\sigma_{c}}\right)(190)+\frac{\sigma_{c}}{\left(\sigma_{f}+\sigma_{c}\right)}(6.32)=144 \mathrm{MeV}
$$

and in steady state the total energy released is $149.5 \mathrm{MeV} / \mathrm{cm}^{3}$-s. If such a steady state reactor produces $7.5 \mathrm{GW}$ of power then the rate of supply of ${ }^{241} \mathrm{Am}$ required is given by:

$$
\frac{d N_{41}}{d t}=V \varphi \sigma_{41} N_{41}=V \varphi \sigma_{42} N_{42}
$$


where $V$ is the volume of the reactor, $\varphi$ the flux, $\sigma$ the absorption cross section and $N$ is the density. With $\sigma_{42}=$ $8000 \mathrm{~b}$, and $N_{42}=10^{18} \mathrm{~cm}^{-3}$ and the flux and size as noted above, we see that the rate of supply of ${ }^{241} \mathrm{Am}$ is $1.2599 \times 10^{-1} \mathrm{~g} / \mathrm{s}$; or $10.885 \mathrm{~kg} / \mathrm{day}$. For a journey that takes 6 months on the basis of a continuous burn, acceleration/deceleration type of trajectory, approximately $2000 \mathrm{~kg}$ of ${ }^{241} \mathrm{Am}$ will be needed.

Returning to the comparison of a ${ }^{242}$ Am-fueled GCR and one that uses ${ }^{235} \mathrm{U}$, with the same moderatorreflector composition and reactor performance characteristics, we should note that the moderator neutron properties remain the same. These include the thermal age, the thermal transport mean free path, the thermal diffusion length, the thermal macroscopic absorption cross section, the thermal diffusion coefficient, and the thermal diffusion time. Clearly, the core properties will change, and these include the absorption cross section, the "interior greyness"

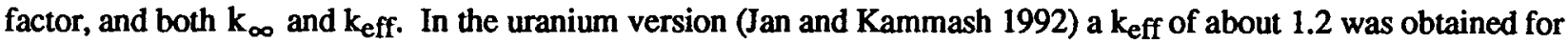
a $7.5 \mathrm{GW}$ reactor operating at $500 \mathrm{~atm}$ pressure and $65,000 \mathrm{~K}$ temperature. Figure 2, which shows the variation of $k_{\text {eff }} v$. the reactor core radius, reveals that $k_{\text {eff }} \approx 1.2$ can be obtained at a radius of $40 \mathrm{~cm}$ in the case of $242 \mathrm{~m} A m$, and that an optimum value of moderator thickness occurs at 0.6 of the core radius. This means that a total radial dimension of $64 \mathrm{~cm}$ will provide the same performance as a ${ }^{235} \mathrm{U}$ reactor with a total dimension of $200 \mathrm{~cm}$, or a reduction in a radial size of about $70 \%$. The reduction in volume is clearly more dramatic, and for space applications this could be significant if not critical.

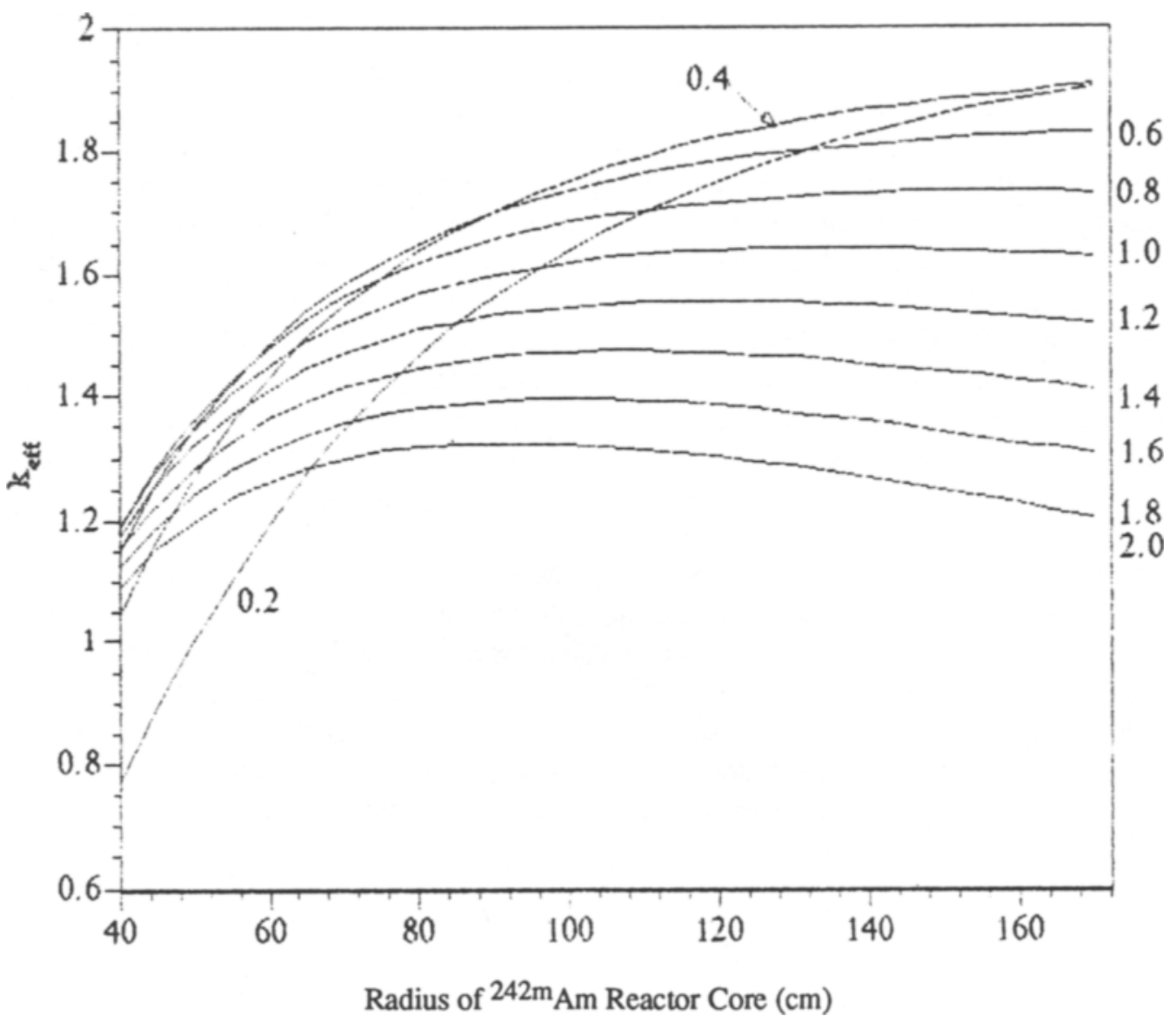

FIGURE 2. $k_{\text {eff }}$ versus Radius of ${ }^{242 \mathrm{~m}}$ Am Gas Core for Different Values of $\alpha$, where $\alpha$ is the Ratio of Moderator Thickness to Reactor Core Radius. $242 \mathrm{~m}$ Am Density is $1 \times 10^{18} \mathrm{~cm}^{-3}$. 


\section{CONCLUSION}

We have examined in this paper the potential use of the americium isotope ${ }^{242 m} \mathrm{Am}$ in a gas core nuclear rocket that could readily meet the objectives of SEI. Due to its large thermal fission cross section we find that a significantly smaller reactor could produce the same propulsion characteristics as a counterpart with ${ }^{235} \mathrm{U}$. Since $242 \mathrm{~m} A m$ is formed by ( $\mathrm{n}, \gamma$ ) reaction on ${ }^{241} \mathrm{Am}$, we have shown that approximately $2000 \mathrm{~kg}$ of the latter will be needed for a six month journey that utilizes a continuous burn, acceleration/deceleration type of trajectory.

\section{Acknowledgments}

One of us (TK) would like to thank Professor Ronald Fleming of the University of Michigan for bringing to his attention the potential use of ${ }^{242 \mathrm{~m}} \mathrm{Am}$ in space applications. This work was carried out at the Nuclear Engineering Department of the University of Michigan.

\section{References}

Jan, T.R. and T. Kammash (1992) "An Antiproton-Initiated Startup Scenario for the Gas Core Nuclear Rocket," in Proc. Nuclear Technologies for Space Exploration, Jackson Hole, WY, 16-19 August 1992.

Kammash, T. and D.L. Galbraith (1992) "Fuel Confinement and Stability in the Gas Core Nuclear Propulsion Concept," AJAA 92-3818, 28th Joint Propulsion Conference, Nashville, TN, 6-8 July 1992.

Poston, D.I. and T. Kammash (1992) "Heat Transfer Model for an Open-Cycle Gas Core Nuclear Rocket," in Proc. Ninth Symposium on Space Nuclear Power Systems, M.S. El-Genk and M. D. Hoover, eds., American Institute of Physics, New York.

Ragsdale, R.G. (1990) Nuclear Thermal Propulsion, a Joint NASA/DOE/DOD Workshop, Cleveland, OH, 10-12 July 1990.

Ronen, Y. and M.J. Leibson (1988) "Potential Applications of $242 \mathrm{~m}_{\text {Am }}$ as a Nuclear Fuel," Nuclear Science and Engineering 99: 278. 